\title{
Development of a Guide to Recommended Print Materials for Diabetes Patient Education
}

\author{
Mary L. Frey, RN \\ Roland G. Hiss, MD \\ Continuing Education and Outreach Core \\ Michigan Diabetes Research and Training Center \\ The University of Michigan Medical School. \\ Ann Arbor, Michigan
}

There are hundreds of current booklets, pamphlets, and manuals available for diabetes patient educa. tion. Everyone, it seems, is writing them from large pharmaceutical companies and publishing houses to small rural hospitals.

A national review of those materials has led to the development of an an. notated resource booklet entitled "Recommended Print Materials for Diabetes Patient Education, 1984." This article discusses the overall results of the review and the methodology used in its formation.

\footnotetext{
Acknowledgements

This project was supported by Public Health Service Grant \#2P60 AM 20572, from the National Institute of Arthritis, Diabetes, Digestive and Kidney Diseases to the Michigan Diabetes Research and Training Center.

We would like to thank Anthony DeVito, II, Louise Garman, Nancy Gladish, Donna Lockwood, and Susan Teza for their critique and review of material and Tana DeClercq for her preparation of this manuscript.
}

Diabetes patient education materials in print format have been developed by numerous educational institutions and diabetes education programs. Many of these materials are extremely good and would be useful to other programs and educators beyond the locale in which they were produced. The problem has been identification of the better materials and national awareness of their availability.

To address this issue, the Michigan Diabetes Research and Training Center has reviewed nationally available patient education material in print format and developed a booklet, "Recommended Print Materials for Diabetes Patient Education." This booklet lists and describes 63 printed educational aids that were judged the best available for use in diabetes patient education. Recommended educational materials are listed by primary content emphasis. Selection of materials appropriate to individual needs can be made by topic, target audience, or potential teaching purpose.

This guide was developed using a process similar to its companion, "Recommended Audiovisual Resources for Diabetes Education, $1983^{\prime \prime}$ and its 1984 edition.

\section{Methods}

Requests for material for review were made to national diabetesrelated organizations. These included commercial, governmental, and voluntary organizations. In all, 303 booklets, pamphlets, and manuals were re- ceived and met the criteria for review, which were: 1) published since 1978 , 2) generally available to any potential user, 3) written for patients, and 4) content related to diabetes and its management.

All programs identified were reviewed by a team of professionals consisting of nurses, a physician, health educators, and administrative staff. Patient target audiences were identified and classified by type and duration of diabetes.

Review included determination of educational effectiveness, applicability to the target audience, accuracy and adequacy of content, quality of production, and overall rating. Selection for inclusion in the booklet was based on overall rating which was judged on a five point scale from poor (1.0) to excellent (5.0). Those programs that achieved a 3.75 or better were chosen and screened for inclusion in the booklet. In subject categories where no materials achieved a rating this high, the next best materials were listed. However, no materials rated below "good" (3.0) were included. For each program with high overall rating, the other characteristics reviewed (educational effectiveness, accuracy, and adequacy of content, etc.) were checked to ascertain that all were of an acceptable level.

\section{Results}

Table I lists the overall ratings of all materials reviewed. Table II indicates the number of programs designed for 
Table I

Overall Ratings of Materials

\begin{tabular}{|l|c|c|}
\hline & $\begin{array}{c}\text { Number } \\
\text { of Programs }\end{array}$ & $\begin{array}{c}\text { Percent } \\
\text { of Total }\end{array}$ \\
\hline Excellent & 24 & $8 \%$ \\
\hline Very Good & 25 & $8 \%$ \\
\hline Good & 98 & $32 \%$ \\
\hline Fair to Poor & 156 & $52 \%$ \\
\hline
\end{tabular}

Table III

Classification of Materials by Content Category

\begin{tabular}{|lr|}
\hline General Facts & 10 \\
Control Measures & 22 \\
Procedures and Techniques & 5 \\
Lifestyle Factors & 8 \\
Personal Hygiene & 4 \\
Long Term Complications & 5 \\
General Audience & 4 \\
Ethnic-Specific & 5 \\
\hline
\end{tabular}

various target audiences, classified by type and duration of diabetes.

The classification of programs by major content category is provided in Table III. Materials listed under General Facts include comprehensive manuals and individual booklets that describe diabetes. Diet, medication, exercise, and monitoring interpretation booklets are listed under Control Measures. Materials specific to psychosocial adjustment, sexual health, and travel are listed under Lifestyle Factors, and foot care aids are listed under Personal Hygiene. No booklet stressing hypoglycemia or hyperglycemia was found that met the criteria.

This guidebook and an updated 1984 edition of Recommended Audiovisual Materials for Diabetes Education are available free of charge from:

Continuing Education and Outreach Core, DRTC

Towsley Center for Continuing Medical Education, Box 057

The University of Michigan Medical Center

Ann Arbor, Michigan 48109

\section{References}

1. Garman, L.W., Lockwood, D., Helms, B and Hiss, R.G. Development of a guide to recommended audiovisual materials on diabetes, 1983. The Diabetes Educator, 1984 , 9(4), 45-46.
Table II

Print Materials for Various Target Audiences

\begin{tabular}{|lr|}
\hline NEW DIAGNOSIS & 26 \\
Type I or Type II using insulin & 13 \\
Type II not on insulin & 4 \\
All patients & 9 \\
\hline ESTABLISHED DIAGNOSIS & 25 \\
Type I or Type II using insulin & 4 \\
Type II not on insulin & 1 \\
All types & 20 \\
\hline ALL PERSONS WITH DIABETES & 3 \\
\hline ETHNIC-SPECIFIC & 5 \\
\hline PUBLIC SERVICE PERSONNEL & 4 \\
\hline
\end{tabular}

\section{NOW AVAILABLE from MERCY HEALTH CENTER, Dubuque, lowa}

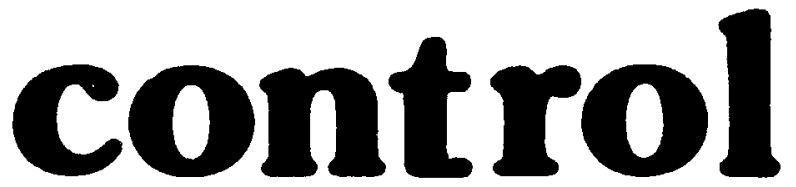

The 1983 A.A.D.E. Allene Van Son Award winning BOARD GAME for ADOLESCENT DIABETICS ... .

Involve your patient in real-life situations with a FUN TEACH TOOL which includes a four-color game board, situation cards, markers, die, rules, winning criteria and instruction manual which includes learner objectives and discussion questions.

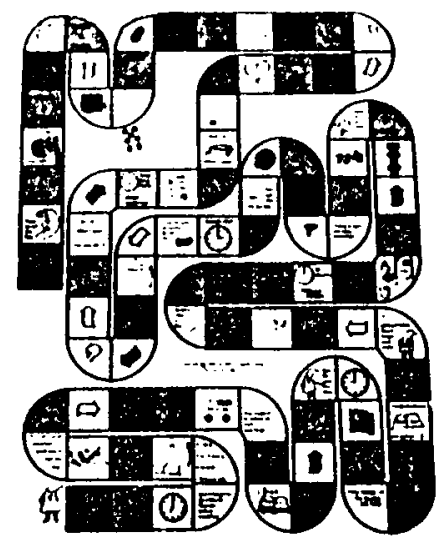

... the BOARD GAME which links the hospital with the real world for diabetic adolescents.

SEND $\$ 25.00$ (plus $\$ 2.00$ shipping/handling) to: CONTROL GAME c/o PATIENT EDUCATION MERCY HEALTH CENTER/MERCY DRIVE/DUBUQUE, IA 52001 